\title{
Causing trouble: the language of learning disability and challenging behaviour
}

There are various and competing ways that different stakeholders, such as professionals, service managers, advocates, and others, understand and talk about learning disability and challenging behaviour. The very terms, themselves, have changed over the years; while 'learning disability' is now commonly used in the UK, many of us still remember language such as 'mental handicap'and other countries (e.g., USA and Australia) more commonly refer to 'intellectual disabilities'. Understandings of, and the language used to describe, what is now termed 'challenging behaviour' have also developed over time. Challenging behaviour has been defined as: 'culturally abnormal behaviour of such an intensity, frequency or duration that the physical safety of the person or others is likely to be placed in serious jeopardy, or behaviour which is likely to seriously limit use of, or result in the person being denied access to, ordinary community facilities (Emerson, 1995, pp.4-5). This language developed from terms such as 'problem behaviour' and was intended to convey that the behaviour was a challenge to services and not something located within or synonymous with a person. Social constructionist research is highly conscious of how language is used, for example, when speaking and writing about learning disability, people with learning disabilities and challenging behaviour. Social constructionism is concerned, amongst other things, with how language is made to serve different purposes and the purposes of different vested interests. Social constructionism informs research and practice. This paper will draw from two studies that take a social constructionist approach. Firstly though, what is social constructionism?

Gergen (1985) identified four principles of the social constructionist perspective. Firstly, to be a constructionist is to take a stance that constantly questions what we know and how we have come to this knowledge. Secondly, a constructionist position is that what we know today hardly ever stands for all time and in all places. A society will witness cultural changes across its history and knowledge also differs across cultures. The third principle refers to the idea that knowledge is sustained through social processes. For example, changes in services for people with learning disabilities reflect how knowledge and values have changed across time. These changes are the outcomes of social processes such as the activities of advocates, the research and evaluation of academics, the writings of professionals, the biographies of people with disabilities and their supporters and so on. Fourthly, knowledge and social actions go together. That is, the actions we take and the justifications that we provide for these actions are influenced by what we know. Consider for example the time not so long ago (prior to 1970) when it was considered that some children with learning disabilities were ineducable i.e., would not benefit from schooling. Now we believe that all children have a right to an education. We once thought that the segregation of people with learning disabilities was good for 
them and for society. Now we think that such social exclusion is wrong. We can deduce from this kind of evidence that knowledge is constantly changing. This means that the things that we know about learning disability and the practices that are informed from this knowledge are somewhat unstable and sometimes uncertain. And yet we must act. Thus at any one time we have to decide what gets accepted as knowledge or theory.

The social processes referred to above take place through language. The things that we speak of in work meetings, conferences, case reviews, the reports that we write, the books, journals, magazines and newspapers that we read use language. Consider the social processes that the professionals on a community learning disability team (CLDT) engage in when they do their work, when they attend to referrals regarding 'challenging behaviour' that are made to seek their interventions in the lives of service workers, families and persons with learning disabilities. Oftentimes a referral is made when the people attending to the needs of a person with learning disabilities experience some trouble in meeting these needs. In the CLDT there are different professionals each informed by the ethos of his or her profession. Each profession might have different theories-knowledge-practices about the cause and solutions to these troubles. A social constructionist approach suggests we notice the language used in services and in documents like referrals. This language use helps us to think about how a service system, like the CLDT, operates and understands itself and its tasks. This in turn will influence how it decides what is possible and 'reasonable' to do. The language that recruits the CLDT's involvement (the referral) may help us to understand how the referring person(s) relate to the person with learning disability; how they are making sense of the difficult behaviours and how they perceive the role of the CLDT. To pursue these questions we conducted two research studies influenced by this perspective. In the first we (Nunkoosing and Haydon-Laurelut, 2011) reviewed the language used in referrals made to a CLDT. The results of this study led us to investigate the source of referrals through interviewing some of the social care managers who had recently made referrals to CLDTs (Haydon-Laurelut, Nunkoosing and Millett, 2014). Both these studies have now been completed and published. The aims of the current article are to present a summary of the findings from this research, to consider its implications for practice and to show how the social constructionist perspective may be of value in both research and practice with people with learning disabilities.

\section{Study 1 - the stories told by referrals to the CLDT}

The referrals for challenging behaviour made to a CLDT over a period of 18 months were reviewed. After anonymising the data the referrals were analysed using Critical Discourse Analysis (CDA) (Fairclough, 1995). This approach enabled us to analyse the way in which the referral texts constructed the referral issues and those involved in them. CDA helps understand how language is used to create and manage identities and relationships. 
The referral form

The referral form itself was subjected to scrutiny given that its structure was likely to shape the referral narrative, picking out those aspects of a situation seen as most relevant, and reflecting dominant concepts in learning disability work. For example, the form showed an implicit acceptance of the premises of applied behaviour analysis in asking about what occurred before and after a 'challenging behaviour', when and where it occurred and in whose presence. This means that the information received by the CLDT has already been filtered through, and shaped by, professionalised technical knowledge. This is not to dispute the validity or otherwise of such knowledge, just to note the extent to which information about an individual's behaviour is already being constructed by the headings available on the referral form.

Thus, the stories in the referral texts were shaped by the referral forms to include more of the information that the CLDT thinks it needs to do its work. Some referrals (see 'John' below) were constructed in the first person, as if having been written by the person with learning disability referring him- or herself. This, again, may have been influenced by the design of the referral form which asked the person referred what help they wanted (although most forms were not written in this way). Referral forms were used almost exclusively by supported accommodation services. When medical practitioners referred someone to the CLDT they wrote letters containing the information about the person and their treatment that they considered relevant. Such professionals appeared to have the power to disregard the administrative constraints put in place by the CLDTR and tell their referral story their own way.

The referral texts

When one becomes a 'client' texts are created about one's life - we might think of these notes, reports, referrals and so on as a kind of unauthorised biography. Goffman (1961) observed the total institution's obsessive accumulation of notes about 'inmates'. Goffman described the total institution as 'a place of residence and work where a large number of like-situated individuals, cut off from the wider society for an appreciable period of time, together lead an enclosed, formally administered round of life'. (Goffman, 1961, pp. 4-5). He also observed several processes in total institutions that were represented in the referrals being considered here. Firstly, 'surveillance', that is the observation and recording of the lives of persons; secondly, 'routinisation' which is the imposition of routines by the organisation; and thirdly, 'mortification', which refers to the truncating of a person's identity i.e., setting limits on who they can be.

Consider the following text taken from the referral of John (not his real name): 
'Verbally aggressive toward other people. Unwilling to listen to reason. I can be very bossy, often involving myself in other people's affairs that do not concern me ... Provocation of others into losing their temper with me, striking out at me or shouting at me...'.

This text contains an invitation to fix or correct one person who is shouted at and hit by others (whose actions don't seem to need the same kind of fixing). As a demeaning description of John's character that is very unlikely to reflect the whole of John's life in the way implied, this is an example of mortification. Goffman wrote of self-debasement being a part of mortification and here the writer of the referral (who, of course, is not John) engages in a kind of proxy self-debasement in writing as if they were John. Coming under the heading of "what I need help with" in the referral form, the text offers the CLDT the position of expert in fixing Johns presumed pathology. Notice the surveillance of John's relationships with others. Most people in group residential settings have not chosen either to live with others or the specific others that they live with. Yet, one of the reasons for his referral is that he seeks to involve himself in the lives of the others with whom he lives! There is much that could be said about the language in this excerpt and how it constructs the referral situation. However, in brief, notice that others 'shout' at John but he is 'verbally aggressive' to them i.e., the description of his behaviour uses a more 'clinical' inflection, suggesting the need for professional intervention.

Consider a second referral:

'Lorraine (not her real name) at time refuses to be assisted to the toilet, when she really needs to go. As Lorraine is able to move around the building (in her wheelchair) the concern is that she will dribble urine around the house, creating a health and safety problem.'

Where is the trouble located here? Is it Lorraine's refusal to be 'assisted' to the toilet or her presumed inability to know her body (a mortification)? Her refusal (at times) may present a challenge to the routinisation of the service and its surveillance of her body. Consider how Lorraine's facility 'to move around the building' makes her and her potentially leaking bladder (although there is no evidence here that she has 'dribble(d) urine around the house') a threat to 'health and safety'. The language of 'health and safety' assists in the creation of a referral problem that may require action from the CLDT, perhaps in the context of the absence of a more typically challenging behaviour 
('aggressive incontinence'?). The CLDT is being sought to make Lorraine less resistant to the ministration of the staff.

Study 1 found referrals located problems in individuals and presented them as persons requiring expert intervention from the CLDT. The study found that the language of referrals reflected some of the concepts Goffman (1961) used in his description of total institutions, that is mortification, surveillance and routinisation. The study also showed that written referrals (and possibly other service documents) were rich sources of data about how learning disability and challenging behaviour are constructed by services.

\section{Study 2 - what referrers say}

Study 1's examination of referral texts inevitably raised questions about how these texts were produced. In study 2 we undertook semi-structured interviews with service managers who had recently referred people to CLDTs. We invited twenty managers by letter and eight agreed to be interviewed. Two professionals who worked across two community teams conducted the interviews. The semi-structured approach allowed the interviewers to be both guided by the findings of study 1 and respond flexibly to the issues that emerged in the interviews and seemed relevant to participants. Interviews, lasting between 60 and 90 minutes, were transcribed and subjected to thematic analysis. Thematic analysis is useful for organising data and a flexible (Braun and Clarke 2006) approach that allows different interpretive positions to be taken - in this case a social constructionist and critical approach to language as described above. The study found one superordinate theme and three subthemes.

\section{Findings}

Study 2 found that writing referrals was a managerial activity (superordinate theme) that served a number of purposes in addition to the obvious one of requesting professional intervention for the person referred. One purpose (subtheme 1) was to legitimise the referring service and its activities. A second was to confirm that the referring service had recourse to the services of the various professionals on the CLDT (subtheme 2), perhaps adding value to the service. A third function of the referral and subsequent contact with the CLDT was concerned with gaining professional support for the 'treatment' decisions that had already been made by the manager (subtheme 3), perhaps when such a decision was not fully supported by other staff in the service. These themes are now illustrated from the interview texts.

Sometimes motivation to refer to the CLDT clearly reflected the referring service's understanding that they required the professional expertise of the CLDT. However, sometimes a referral was made in response to the request of another professional or a parent/relative of the person with learning 
disability. In these cases referring services may or may not have been in agreement with the need to refer to the CLDT:

'Another social care worker asked us to put the referral in...I think the staff seemed to feel like 'hold on a minute...'

'... because her parents... always insisted on her having some kind of therapy'

It seems strange that the social care worker did not make the referral in her/his own right though s/he may not have felt that he/she had the legitimacy to do so. Interestingly, in this case, the staff of the group home had reservations about being asked by an outsider to make the referral. This may have reflected their different experience of the "problem" or, perhaps, their resentment at being asked to refer.

Whatever the reason for producing a referral to the CLDT it was seen as an act that could either bolster the image of the service or bring needed expertise into the group home:

'Well, it's ensuring that if you are putting referrals in that, you know, you are having the right people coming into the service and you have got the right resources in place'.

'Sometimes we need professional help because we have done everything we possibly can'.

Service managers are often experienced and hold management qualifications but may not have the professional qualifications of CLDT members. The manager's experience, expertise and authority is also a source of advice for care staff about practices in the group home. Sometimes, however, managers reported making referrals to obtain the validation of the CLDT, perhaps because they were unsure themselves or concerned to convince their staff of the rightness of their approach:

'...because I didn't feel qualified to make that decision really. It turned out to be straightforward. When I refer anybody I usually have an idea as to what I think should be happening myself, but I am not qualified to make those decisions.'

'We'd already put the action plan in (before we made the referral)'.

By virtue of their professional standing, CLDT members were seen as having authority and knowledge that could be invoked by a manager through the referral process:

'...there are certain things that we have to be careful with, particularly sex education, safeguarding and things like that, that legally we kind of have to cover our own backs. We can't be seen to just be going ahead in case there's a problem down the line.' 
In some instances a person was referred even when there was no need for the expertise of the CLDT:

'We kind of need to refer them but not really for anything...the (community learning disability) team need to know that we've got somebody here and obviously in the beginning the team need to know we existed as a home. The referral form didn't really do anything because we didn't want anything, we were just saying ' $\mathrm{Hi}$, this person has just moved in and we want you to be aware of it. Then of course they (the CLDT) contact us and say 'why have you referred?' ... well we haven't, we don't want anything from you but we do need you to know, and bearing in mind this is autism and quite severe challenging behaviour'.

This illustrates how referrals become part of the 'biographical' documents that follow a person when he or she becomes a client of health and social care services.

Service managers implied that their views were generally endorsed by the CLDT, though it should be noted, of course, that the views of CLDT members were not directly sought:

'I have never been corrected (by the CLDT) so I don't know how I'd feel if I was corrected ha-ha. I don't know what I'd do if they were to say 'what the hell are you thinking?'

'Before I make that phone call to the community team, and the professionals I need to speak to, I'll already have some points there as to what I'm doing... 'this is what I am going to do, what do you think about it?' and 99.9 per cent of the time they'll come back and say 'yeah, that's fine'.

It is interesting to note how the person who is the focus of these 'doings' is missing. Persons with learning disabilities were missing from the accounts of managers in study 2.

The CLDT works as a team whilst the manager appears to have personal authority to decide what happens to the people with learning disabilities who depend on the services they manage. It would clearly be of interest to follow up the research reported here with a study of the experiences of CLDT members. While such experiences may (or may not) be at odds with the views of managers, it would also be interesting to explore the 'doings' of CLDT members from a social constructionist perspective.

\section{Conclusion \& Implications}

It is in no way the intention of the current article to downplay the distress associated with challenging behaviour for people with learning disabilities, their families and paid carers. Professional intervention (e.g., from CLDT members) undoubtedly has an important role to play in supporting the 
community residence and quality of life of individuals whose behaviour may sometimes be described as challenging.

Nonetheless, in referrals to CLDTs all kinds of events and actions may be constructed as challenging. The two studies described show that professional labels such as 'challenging behaviour', other 'official' terms such as 'health and safety', demeaning language describing persons with learning disability and referrals for challenging behaviour more generally may be employed more for the purposes of the referrer than for the benefit of those being referred.

The studies found referrals for challenging behavior may be used to enhance the legitimacy of the referring service, confirm their support practices, and empower management decisions. The language of referrals constructs identities of the referred person and others, including CLDT professionals. Additionally, study one suggested the presence of institutional practices (surveillance, mortification and routinisation), a matter of some concern in contemporary services. In particular, the first person narrative used in one referral seemed a perversion of person-centeredness.

The studies found no evidence of the person with a learning disability having the power to define, label or make meaning of their own behaviours or those of others including the behaviours of staff and managers. Indeed, meaning was more likely to arise from the administrative processes (e.g., forms used, service jargon and labels) of contemporary services. Such processes should be designed and used with care to ensure that individuals are described accurately and respectfully.

Those of us who deal with referrals and other texts might ask questions such as:

How is this person being constructed in this text?

Is this how he or she would choose to be described?

What stories are being told in this particular document and with what consequences?

In conclusion, this article has indicated the importance of attention to the referral process and the language used in referrals. The language used has the power to tell us much about the relationships and practices of services supporting people with learning disabilities.

\section{References}

Braun, V. and Clarke, V. (2006), "Using thematic analysis in psychology", Qualitative research in psychology, Vol. 3 No. 2, pp. 77-101.

Drinkwater, C. (2005), "Supported Living and the Production of Individuals", In Tremain, S. (Ed.), Foucault and the Government of Disability, University of Michigan Press, Ann Arbor, pp. 229-244. 
Emerson, E. (1995), Challenging Behaviour. Analysis and Intervention in People with Learning Difficulties, Cambridge University Press, Cambridge.

Fairclough, N. (1995), Critical Discourse Analysis, Longman, London.

Gergen, K. (1985), "The social constructionist movement in social psychology", American Psychologist, Vol. 40, pp. 266-275.

Goffman, E. (1961), Asylums: Essays on the Social Situation of Mental Patients and other Inmates, Penguin Books, Harmondsworth.

Goffman, E. (1963), Stigma: Notes on the Management of Spoilt Identity, Penguin Books, Harmondsworth.

Haydon-Laurelut, M., Nunkoosing, K. and Millett, E. (2014), “"The seal of approval': referring adults with intellectual disabilities and challenging behaviour to community learning disability teams", Disability \& Society, Vol. 29 No. 2, pp. 290-302.

Nunkoosing, K. and Haydon- Laurelut, M. (2011), "Intellectual disabilities, challenging behaviour and referral texts: a critical discourse analysis”, Disability \& Society, Vol. 26 No. 4, pp. 405-417. 